\title{
Effect of the Isostretching Method on Lumbar Pain and Flexibility of the Lumbar Spine in Elderly Women
}

Ana Karine de Figueiredo Moreira ${ }^{4}$, Juliana Lopes Miranda de Sene1, Samara Bezerra Dourado, Mariana de Souza Costa2,3, José Carlos Rapozo Mazulo Neto1,2, Ramon Handerson Gomes Teles 1,2, Yago Medeiros Dutra1,2, Luan Filipe Lima Freitas 1,2, Isabela de Souza Braúna2, Saul Barbosa de Oliveira 2,3, Janyere Alexandrino de Sousa1,2, Gilberto Santos Cerqueira ${ }^{3}$, Baldomero Antônio da Silva Kato ${ }^{3}$, Marcelo de Carvalho Filgueiras ${ }^{2,3}$

\section{Abstract}

Introduction: Lower back pain is defined as the presence of pain, with or without stiffness, located in the lower region of the spine, between the last costal arch and the gluteal fold. In the elderly, inherent factors of aging, such as inactivity, postural instability and a decrease in neuromuscular response, contribute to its occurrence. Although studies have pointed to a reduction in prevalence in this population, when the severe forms of lower back pain are analyzed, there is a significant increase.

Objectives: The aim of this study was to evaluate the effect of the Isostretching method on the pain and flexibility of the lumbar spine in the elderly.

Methods: The sample was composed of 14 women with lower back pain and a mean age of 70 years. 24 isostretching sessions were performed and assessed regarding the pain and flexibility of the lumbar spine. The elderly were evaluated before the start and after the 12th and 24th session, through a specific evaluation that included data from anamnesis, history, a specific test (Schober), goniometry of the lumbar spine, and the Visual Analogue Scale (VAS).

Results: The results reveal that there was a reduction in the sensation of pain and a gain in flexibility after the isostretching sessions.

Conclusions: It was concluded that the method the method was effective in the improvement of the variables under study.
1 Federal University of Piauí, Parnaíba, Piauí, Brazil.

2 Federal University of Piauí. Laboratory of Muscle Morphology and Physiology (LAMFIM), Biomedical Sciences Graduate's Program, Parnaíba, Piauí, Brazil.

3 Federal University of Piauí, Biomedical Sciences Graduate's Program, Parnaíba, Piauí, Brazil.

4 Federal University of Ceará, Fortaleza, Ceará, Brazil.

Contact information:

Marcelo Carvalho Filgueiras.

Address: Av. São Sebastião, 2819, Santo Expedito. Parnaíba, PI, Brazil.

Tel: (85) 99650685.

झ professormarcelo@ufpi.edu.br

Keywords

Lower Back Pain; Range of Motion; the Elderly. 


\section{Introduction}

Lower back pain (or lumbago) is defined as the presence of pain, with or without stiffness, located in the lower region of the spine, between the last costal arch and the gluteal fold [1]. In addition to pain, aspects related to functionality have also been described, such as difficulties in performing daily activities and the effects on personal, work and social life [2]. It is a common and socially quite costly condition, since it that can lead to absenteeism or even work disability. In Brazil there is a paucity of data regarding the epidemiology, but studies have pointed out that virtually all individuals have suffered at least one episode in the course of their lives [3]. The social costs are related to the physical limitations caused by the pain and emotional problems such as depression [4], since the most affected population is aged 40 to 69 years, an individual's life period associated with the highest labor productivity [5].

Despite its high incidence and importance to public health, its etiology and natural course are very little understood with its cause being idiopathic in many patients [6]. No specific causative factor is known and the cause of the disease is considered to be multifactorial, which makes its prevention and treatment harder. Muscular imbalance, however, such as weakness of the abdominal muscles and shortening of the extensor muscles, has been observed as one of its main causes $[6,7]$.

Biomechanically, the lumbar spine plays a key role in the absorption of forces, such as those exerted by body weight, muscle action and external forces. In healthy individuals, its stability is maintained by the coordinated contraction of the flexor and extensor muscles of the trunk. In patients with lower back pain, a weakness of these muscle groups can be seen [8]. As such, there is a direct relation between muscle strength, especially in the trunk, and the occurrence of lower back pain. The elderly experience widespread functional loss, including in the strength of their trunk muscles, which enables the onset of this condition.
In the elderly, inherent factors of aging, such as inactivity, postural instability and a decrease in neuromuscular response, contribute to its occurrence. Although studies have pointed to a reduction in prevalence in this population, when the severe forms of lower back pain are analyzed, there is a significant increase [5]. It is common for the elderly to assume a sitting posture, thus maintaining the lumbar spine bent for long periods of time, which overloads the musculoskeletal structures of the region [9].

Several treatments for lower back pain have been suggested, and there seems to be a consensus regarding the prescription of regular exercise. The most efficient modalities, however, are still being debated [10]. Several therapeutic exercises have been proposed in the last decades, most notably those related to the intersegmental stability of the lumbar spine [11]. In the different physiotherapy approaches, such as Global Postural Re-education, Hydrotherapy, and the Pilates method, trunk muscle toning and balance is a primary factor. Despite their diversity, these treatments lack scientific studies to establish their effectiveness and standardize the intervention [11, $12]$. As such, the relevance of research on the application of therapeutic exercises in the treatment of lower back pain is established.

In this context, the isostretching method is prescribed as an alternative therapy. Created in France in 1974 by Bernard Redondo, it is a global postural gymnastic exercise that focuses on strengthening and flexibility [13]. Also known as balance kinesiotherapy, its practice involves the adoption of postures that promote the coordinated work of agonist and antagonist muscles, with mild isometric and moderate eccentric contractions that seek to preserve the physiological spinal curvatures, providing body awareness and postural alignment [14-16].

According to the originator of the method, the foundations of the technique are active and aware respiratory control, body positioning and intense muscle work [17]. It is considered to be a global postural method because the whole body is worked 
through the adopted postures [1]. The method also involves the coordination and control of breathing [18]. It is a relatively new method in Brazil, albeit one that is already being practiced by a large number of physiotherapists. Scientific studies are still scarce, however $[14,19]$. The objective of this study is to evaluate the effects of isostretching on pain and flexibility of the spine in elderly women with the symptoms of chronic lower back pain.

\section{Methods}

This study uses a quantitative, interventionist, descriptive and longitudinal approach, with the values obtained being measured statistically through the application of quantitative methods of research for a better visualization of the problem under study.

The ethical guidelines were followed, ensuring the confidentiality and anonymity of participants. Each individual was informed about the objectives of the study and confirmed his participation by signing the Informed Consent Form (ICF). The project was submitted to the Ethics Committee for Research of the Federal University of Piauí and approved under the number: 750.888 .

The sample was chosen for convenience. Initially 35 elderly (05 men and 30 women) were assessed, ranging in age from 60 to 80 years. Twelve elderly women with a mean age of $70.8 \pm 4.6$ years, who had (mild to moderate) pain symptoms and decreased flexibility of the lumbar spine, identified previously through a physical therapy evaluation, were included. We excluded 12 elderly (05 men and 07 women) with the following exclusion criteria: acute and incapacitating pain condition, advanced cognitive impairment, severe orthopedic disorders, and other conditions that prevented the effective and safe implementation of the Isostretching. Additionally, 11 elderly women were excluded for attending less than $75 \%$ of the total of 24 sessions.

The research was divided into three steps: selection screening, specific evaluation (of pain and flexibility) and intervention, developed and implemented by the researchers based on the scientific literature.

The 10 postures chosen for the intervention in this work emphasized the anterior and posterior muscle chain of the trunk and lower limbs, the anterior interior chain of the pelvis, in addition to working the respiratory muscles.

The elderly were evaluated before the start and after the 12th and 24th session, through a specific evaluation that included data from anamnesis, history, a specific test (Schober), goniometry of the lumbar spine, and the Visual Analogue Scale (VAS).

The Schober test was applied to identify the lumbar spine's limitation of movement. The patient remained in upright position while the examiner marked out a space of $15 \mathrm{~cm}$ : measured $10 \mathrm{~cm}$ above and $5 \mathrm{~cm}$ below the spinous process of $\mathrm{L} 5$. The patient was then asked to perform a maximum flexion without bending the knee, measuring the distance of the points during each movement. The goniometric measurement of the range of motion of: the dorsolumbar flexion (trunk forward), dorsolumbar extension (trunk backwards) and left and right lateral tilt of the trunk, were carried out with a $20 \mathrm{~cm} C A R C I^{\circledR}$ goniometer.

After this evaluation, the patients were trained for two weeks after the initial assessment in order to ensure a basic level for the execution of the movements and to familiarize them with the exercises. On the first day of training, they received a script that included the 10 selected postures for the application of the method under study. In the following sessions, the images of the postures were presented in Power Point slides and projected with the aid of a multimedia data show device. The sessions on the method took place three times per week, on alternate days, with a duration of 60 minutes each, for a period of 2 consecutive months and carried out in group.

The vital signs - heart rate, blood pressure and respiratory rate - were measured prior to each ses- 
sion to ensure that the practice of the postures didn't pose any risk to the volunteer. The sessions were divided into: 5 minutes of stretching in general in order to prepare the body for the activity; 50 minutes for the practice of the 10 selected postures, which were carried out in standing, tilted, sitting and lying down positions, and finally, 5 minutes of relaxation exercises, walking or stretching.

The data were organized so as to compare them with the responses of the assessed variables at the various stages of the study. The analyses between the moments were performed with the Analysis of Variance (ANOVA) with a post hoc Tukey test in the samples of normal distribution and the KruskalWallis test with a post hoc Dunn's test in samples of non-normal distribution. The normality of groups was analyzed using the Shapiro-Wilk test. The considered level of significance was $p \leq 0,05$.

The tabulation of results was done in the Microsoft Office Excel 2010 software, and the normality calculations were performed on the Bioestat software. Data comparison and chart development were done on the GraphPad Prism 5 software.

\section{Results}

On the whole, our results revealed that the isostretching method was effective in the treatment of lower back pain in elderly women. Both in the first evaluation, after 12 intervention sessions, and second evaluation, after 24 sessions, an improvement in the evaluated parameters could be observed, such as a reduction in pain and improvement of flexibility.

Figure 1 shows the result for the variation of pain as assessed by the Visual Analog Scale (VAS). In the first evaluation, the VAS mean was $5.8 \pm 1.3$, which is considered moderate, but there was a significant reduction of lumbar pain measured through VAS when the initial responses of the group were compared with the treatment outcomes. In the second evaluation the result was $4.4 \pm 1.0$ and in the last evaluation, after 24 sessions, it was $3.3 \pm 0.9$.
Figure 1: Comparison of the Visual Analogue Scale scores of the various moments under analysis.

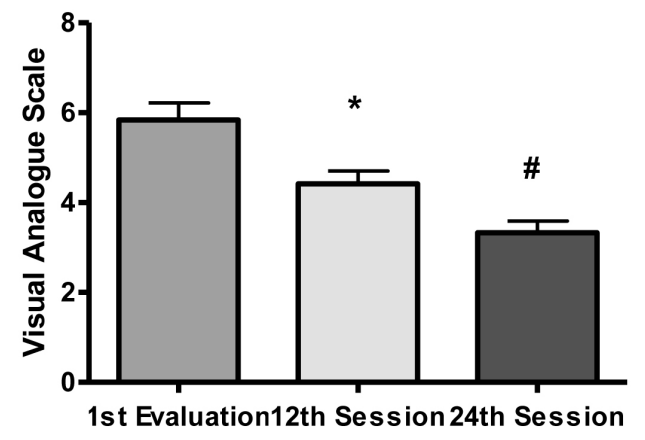

ANOVA; $p<0.0001 ; *$ : $p<0.01$ as compared to baseline, $\#: p<0.001$ as compared to baseline.

Figure 2: Comparison of the Schober Index scores of the various moments under analysis.

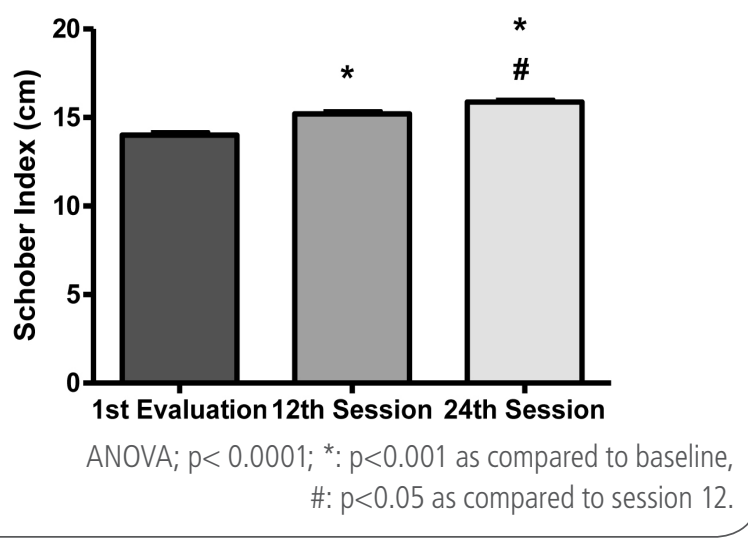

Figure 3: Comparison of the dorso-lumbar flexion ( Kruskal-Wallis; $\mathrm{p}<0.0001$ ) and extension (Kruskal-Wallis; $p=0.0006$ ) measurements of the various moments under analysis.

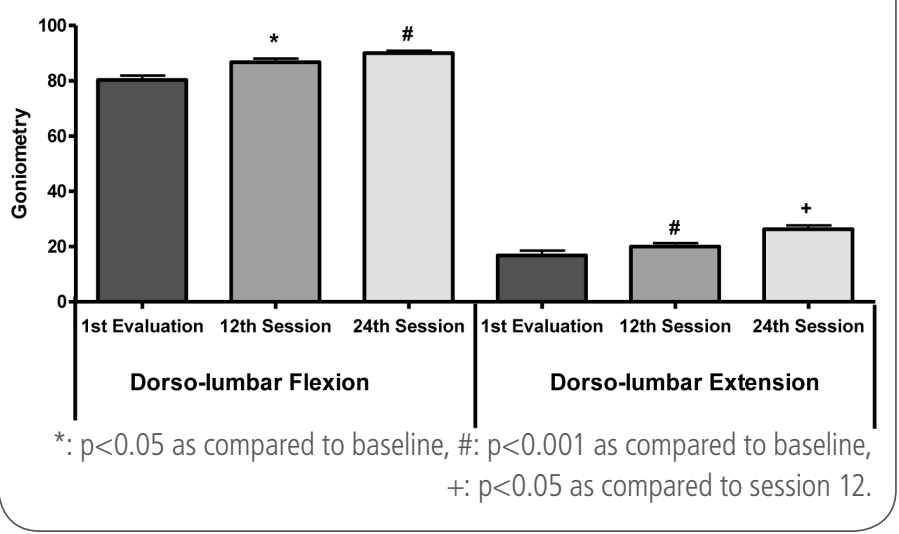


With respect to the flexibility of the lumbar spine, a significant gain could be observed as measured by the Schober index (Figure 2) and by the dorsolumbar flexion and extension goniometry (Figure 3). The Schober index ranged from $14.0 \pm 0.7$ in the first evaluation to $15.9 \pm 0.5$ in the last. This result is quite positive, given that an adequate level of flexibility is essential for the functionality and independence of the elderly (BATAGLIA et al. 2014). The gain in flexibility in lumbar spine flexion varied from $80.3 \pm 5.3$ to $90.0 \pm 3.0$, and in extension from $16.8 \pm 6.1$ to $26.3 \pm 4.8$, when considering the initial and final evaluations. There is a gain of approximately 100 in each situation.

\section{Discussion}

Demographic changes resulting in a growing aging of the population have been observed in most countries. This fact makes it necessary to study the pathophysiological events inherent in the condition of the elderly. In this context, problems related to the vertebral column are quite common, answering for a limitation and poor quality of life, especially at this stage of life. Pains in this region reach a prevalence of up to $80 \%$ in the general population, representing an important public health problem [20]. The direct costs, such as those related to outpatient treatments and hospitalizations, and the indirect costs, such as loss of productivity and absenteeism, are a significant burden on the health care systems [21].

Our data suggest that isostretching is an effective resource for the treatment of pain, since there was a significant reduction in pain during the treatment, as can be seen in Figure 1. Similar results were obtained by Doughert and collaborators [22], where an intervention with exercises was also effective in reducing the pain as assessed by the VAS. These satisfactory results regarding pain reduction are caused by the practice of physical activity to which the elderly were submitted. If, on the one hand, a sedentary lifestyle is a factor in generating spine pathologies, on the other, the practice of regular exercise provides health benefits, such as improvements in posture and muscle strength that reflect on the general condition of the individual $[13,23]$. Physical exercise is beneficial for the elderly not only in the treatment of lower back pain, but also in a global manner, improving, maintaining, or at least minimizing the effects of aging on the musculoskeletal system.

The effect of the isostretching method on lumbar pain was observed by Macedo and collaborators [1] in young women, but presenting significant results only after 20 sessions. Other studies, however, corroborate our results, with the treatment reducing pain already after the first interventions and with this result also being repeated in the second evaluation [24]. Silva and Inumaru concluded that Isostreching method can be an effective tool for the treatment of patients with chronic low back pain and in order to reduce disability and pain [25]. An important point regarding the positive effect of the method on pain is the fact that another important symptom observed in patients with lower back pain is also influenced, namely depression. The pain can cause depression because it restricts social and family life, leisure and work activities. The opposite is also true for the same reasons [4].

A tendency toward inactivity can be observed in elderly women, be it for fear of falling or because of the presence of pain, which leads to discomforts in the spine and generalized muscle changes. The relationship between aging, pain intensity and greater muscle deficiency is explained by the fact that aging can result in progressive degenerative changes of the spine. In this case, could result in weakness of the musculoskeletal system, causing painful episodes, since these tissues have nociceptors that are capable of generating noxious stimuli, suggesting that the oldest individuals are most vulnerable to problems associated with the lumbar spine [25]. The low impact characteristics and the safety of the 
static postures in isostretching explain the good acceptance of the method among the participants of the study, especially with the acquisition of positive results regarding pain.

The muscles of the trunk are responsible for the stability of the spinal column through the coordinated action of their flexors and extensors. These muscles are weakened in patients with lower back pain [8]. Methods that promote the stretching and strengthening of the paravertebral muscles, therefore, seem to have positive results in the treatment of lower back pain [25]. In addition to the effects of isostretching on lumbar pain, its influence on the flexibility was also addressed in this study. Its importance lies in the fact that it is a variable capable of interfering with the painful symptoms and functional independence [23]. One can therefore infer that the improvement of pain produces an increase in flexibility and the opposite is also true.

Studies have shown that the postures used during the practice of isostretching are capable of improving flexibility in both healthy individuals and in those with spinal problems $[13,15,27]$. This corroborates our results, which revealed a significant gain in the articular range of motion even after the first interventions. The gain in flexibility provided by the practice of isostretching is beneficial not only for lumbar pain, but also for the realization of daily activities and the reduction of the risk of injuries. The risk of falls in the elderly, for example, is reduced in individuals who practice flexibility exercises, especially of the spinal column [28].

Previous studies have pointed to the relationship between pain and flexibility in elderly patients [23]. We observed an improvement in both variables already after the first 12 sessions with isostretching. An important aspect in this study is the fact that the exercises were done in groups, and in a basic care center, proving to be a cheap and efficient alternative for the public health services, in addition to promoting socialization and recreation for the elderly, which has been pointed out as being effective in improving skills, muscle stretching and flexibility in the elderly [6]. Sofi and colleagues [10] observed the benefits of community exercises in patients with lower back pain, even in the age group of 65 years.

Based on the analysis of the data of the study, the conclusion can be drawn that the isostretching method is effective in the treatment of lower back pain in elderly patients, enabling a reduction in pain and increase in flexibility. Physical exercises in groups are beneficial for the elderly and can be applied in public service strategies, becoming an alternative for the physical therapy interventions of primary care health centers. The realization of other studies, with a larger population in order to explain more fully the effects of this method, is suggested.

\section{Conflicts of Interest}

All authors declare there were no conflicts of interest.

\section{References}

1. Macedo CSG, Debiagi PC, Andrade FM. Efeito do isostretching na resistência muscular de abdominais, glúteo máximo e extensores de tronco, incapacidade e dor em pacientes com lombalgia. Fisioter Mov. 2010; 3(1):113-20.

2. Riberto M, Chiappetta LM, Lopes KAT, Battistella LR. A experiência brasileira com CORE SET da Classificação Internacional de Funcionalidade, Incapacidade e saúde para lombalgia. Coluna. 2011; 10(2): 121-6.

3. Artus $M$, Windt DAVD, Jordan KP, Hay EM. Low back pain symptoms show a similar pattern of improvement following a wide range of primary care treatments: a systematic review of randomized clinical trials. Rheumatology 2010; 49:2346-56.

4. Garbi MOSS, Hortense P, Gomez RRF, Silva TCR, Castanho ACF, SOUSA FAE. Intensidade de dor, incapacidade e depressão em indivíduos com dor lombar crônica. Rev Latino-Am Enfermagem. 2014; 22(4):569-75.

5. Hoy D, Bain C, Williams $G$, et al.: A systematic review of the global prevalence of low back pain. Arthritis Rheum. 2012, 64: 2028-37.

6. Cho KH, Beom JW, Lee TS, Lim JH, Lee TH, Yuk H. Trunk Muscles Strength as a Risk Factor for Nonspecific Low Back Pain: A Pilot Study. Ann Rehabil Med. 2014; 38(2):234-40. 
7. Ashraf A, Farahangiz S, Jahromi BP, Setayeshpour N, Naseri M, Nasseri A. Correlation between Radiologic Sign of Lumbar Lordosis and Functional Status in Patients with Chronic Mechanical Low Back Pain. Asian Spine J. 2014; 8(5):565-70.

8. Lee J, Yang S, Koog Y, Jun H, Kim S, Kim K. Effectiveness of Sling Exercise for Chronic Low Back Pain: A Systematic Review. J. Phys. Ther. Sci. 2014; 26: 1301- 06.

9. Battaglia G, Bellafiore M, Caramazza G, Paoli A, Bianco A, Palma A. Changes in spinal range of motion after a flexibility training program in elderly women. Clin Interv Aging. 2014,9:653-60.

10. Sofi F, Molino-Nova R, Nucida V, Taviani A, Benvenuti F, Stuart M, Weinrich M, Cecchi F, Abbate R, Gensini GF, Macchi C. Adaptative physical activity and back pain: a non-randomised community-based intervential trial. Eur J Phys Rehabil Med. 2011; 47:543-9.

11. Ribeiro CAN, Moreira D. O exercício terapêutico no tratamento da lombalgia crônica: uma revisão da literatura. R. bras. Ci. e Mov. 2010; 18(4):100-8.

12. Sung PS. Disability and back muscle fatigability changes following two therapeutic exercise interventions in participants with recurrent low back pain. Med Sci Monit, 2013; 19: 40-48.

13. Hespanhol Junior LC, Oliveira KTF, Oliveira TGV, Girotto N, Carvalho ACA, LOPES AD. Efeito do método Isostretching na flexibilidade e nível de atividade física em indivíduos sedentários saudáveis. R. bras. Ci. e Mov. 2011; 19(1):26-31.

14. Mann L, Kleinpaul JF, Weber P, Mota CB, Carpes FP. Efeito do treinamento de Isostretching sobre a dor lombar crônica: um estudo de casos. Motriz. 2009; 15(1):50-60.

15. Moraes JMM, Coelho KO, Carvalho ACA, Prado RAP, Lopes AD. Efeitos do Isostretching na dor, flexibilidade, qualidade de vida e nível de atividade física em adultos com escoliose. Ter Man. 2011; 9(44):362-65.

16. Cepeda CC, Rodacki ALF, Persch LN, Silva PP, Buba S, Dressler VF. Efeitos do método isostretching sobre parâmetros morfológicos e sobre um conjunto de testes motores em idosas. Rev Bras Cineantropom Desempenho Hum 2013, 15(5):604-15.

17. Redondo, B. Isostretching: la gimnasia de la espalda. Barcelona: Paidotribo. 2002.

18. Carvalho AR, Assini TCKA. Aprimoramento da capacidade funcional de idosos submetidos a uma intervenção por isostretching. Rev Bras Fisioter. 2008; 12(4):268-73.

19. Monte-Raso VV, Ferreira PA, Carvalho MS, Rodrigues JG, Martins CC, Lunes DH. Efeito da técnica isostretching no equilíbrio postural. Fisioter Pesq. 2009; 16(2):137-42.

20. Lemos TV, Albino ACG, Matheus JP, Barbosa AM. The Effect of Kinesio Taping in Forward Bending of the Lumbar Spine. J. Phys. Ther. Sci. 2014; 26: 1371-75.

21. Macedo LG, Bostick GP, Maher CG. Exercise for Prevention of Recurrences of Nonspecific Low Back Pain. PHYS THER. 2013; 93:1587-91.
22. Dougherty PE, Karuza J, Savino D, Katz P. Evaluation of a modified clinical prediction rule for use with spinal manipulative therapy in patients with chronic low back pain: a randomized clinical Trial. Chiropr Man Therap. 2014, 22:41.

23. Hauser, E, Martins EF, Griebler EM, Gonçalves CJS, Freitas CLRA, Teixeira AR, Gonçalves AK. Relação entre flexibilidade e dor em idosos ativos. Revista Kairós Gerontologia. 2013; 16(5):.61-71.

24. Adorno MLGR, Brasil-Neto JP. Assessment of the quality of life thro ugh the SF-36 questionnaire in patients with chronic nonspecific low back pain. Acta Ortop Bras. 2013; 21(4):202-7.

25. Silva PHB, Inamaru SMSM. Assessment of pain in patients with chronic low back pain before and after application of the isostreching method. Fisioter MOv. 2015; 28(4): 767-77.

26. Durante $H$, Lemes EC, Vasconcelos $M$. Comparação do método Isostretching e cinesioterapia convencional no tratamento da lombalgia. Semina. 2009; 30(1): 83-90.

27. Frutos $A L$, Boldrini $C M$, Ferrari $D$, Behne $G R$, Santos $L C$, Silva PHL, Carvalho ARC, Pegorano M, Bertolini GRF. Comparação do alongamento estático e isostretching na flexibilidade da cadeia muscular posterior. Rev Inspirar. 2014; 6(4):6-10.

28. Martinez-Lopes E, Hita-Contreras F, Jiménez-Lara PM, LatorreRomán P, Martínez-Amat A. The Association of Flexibility, Balance, and Lumbar Strength with Balance Ability: Risk of Falls in Older Adults. J Sports Sci Med. 2014; 13:349-57.

\section{Publish in International Archives of Medicine}

International Archives of Medicine is an open access journal publishing articles encompassing all aspects of medical science and clinical practice. IAM is considered a megajournal with independent sections on all areas of medicine. IAM is a really international journal with authors and board members from all around the world. The journal is widely indexed and classified Q2 in category Medicine. 